\title{
AS PERSPECTIVAS DO DIREITO PROCESSUAL CIVIL BRASILEIRO A PARTIR DO ESTUDO DA FASE PRETRAIL DO PROCESSO CIVIL NORTE- AMERICANO
}

\section{PROSPECTS OF BRAZILIAN CIVIL PROCEDURE LAW FROM THE STUDY OF PRETRAIL}

${ }^{1}$ Rafael Gomiero Pitta

2 Jéssica Amanda Fachin

\section{RESUMO}

A proposta do presente trabalho é, após analisar as principais características da fase pretrial do sistema estadunidense, considerar alguns aspectos do sistema daquele país e propor soluções para problemas vivenciados na cultura judicial brasileira. Para alcançar este objetivo é preciso em primeiro lugar investigar sistemas diversos, compreender a cultura processual arraigada nos operadores, implantar uma visão mais aberta e acima de tudo, conhecer a própria cultura jurídica, compreende-la profundamente e questionála por seus métodos e por seus resultados.

Palavras-chave: Pretrail, Jurisdição, Efetividade

\begin{abstract}
The purpose of this paper is, after analyze the main characteristics of the pretrial phase of the US system, consider some aspects of that country's system and propose solutions to problems experienced in the Brazilian judicial culture. To achieve this goal we must first investigate various systems, understand the procedural culture rooted in operators deploy a more open vision and above all, know their own legal culture, understand it deeply and question it for its methods and its results.
\end{abstract}

Keywords: Pretrail, Jurisdiction, Effectiveness

\footnotetext{
${ }^{1}$ É professor e Coordenador do Núcleo de Prática Jurídica na Faculdade Londrina, Unilondrina - PR, (Brasil). É professor na Faculdade Catuaí - PR, (Brasil). E-mail: rafapitta22@gmail.com

${ }^{2}$ Possui Mestrado em Ciência Jurídica pela Universidade Estadual do Norte do Paraná, UENP - PR, (Brasil). Atualmente é professora na Faculdade Londrina, UNILONDRINA - PR, (Brasil).

E-mail: jessicaafachin@gmail.com
} 


\section{INTRODUÇÃO}

Dos problemas relatados pelos usuários do sistema Judiciário Brasileiro, sem dúvida o mais recorrente é a lentidão do trâmite processual. A análise superficial a respeito das consequências deste problema revela que a morosidade gera em grande parte dos casos a inefetividade da justiça, o que em última instância conduz a sérios prejuízos ao exercício da cidadania e interfere diretamente no cotidiano das pessoas, especialmente em relação ao acesso à justiça.

O grande volume de processos pendentes de julgamento nas instâncias judiciárias é o principal fator de lentidão dos processos, e este problema não passa despercebido pelos órgãos de controle e fiscalização do Poder Judiciário Brasileiro, que se empenha em diminuir o volume de processos em trâmite no país aplicando medidas que em suma, incentivam a composição entre as partes e limitam o acesso aos recursos pelo critério de admissibilidade procedimental.

Embora o Sistema Judiciário, através do Conselho Nacional de Justiça venha de fato empreendendo esforços no sentido de contornar a grave situação de morosidade gerada pelo acúmulo de processos que, as reformas e investimentos em infraestrutura e pessoal vêm gerando resultados insatisfatórios, que apontam para soluções paliativas. É verdade que os magistrados lidam com metas significativas e se desdobram para realizar as tarefas judicantes, tais como presidir a instrução processual e decidir uma quantidade enorme de ações, no entanto, tal esforço resolve apenas uma pequena parcela do problema, mais relacionado ao acesso à justiça do que à redução do tempo no trâmite processual.

Entre as soluções adotadas até aqui visando promover maior acesso à justiça, estão: a) aumento de recursos humanos (juízes e servidores); b) alterações legislativas que incentivam a conciliação; c) soluções alternativas e conflito; d) mutirões e campanhas que visam impedir litígios judiciais. Tais medidas são extremamente válidas, no entanto, não impactam na diminuição efetiva de processos. As soluções apontadas até aqui podem, com esforço, alcançar uma redução na quantidade de processos ingressantes, mas na prática não alcança a diminuição dos casos, como se poderá confirmar a seguir das estatísticas trazidas pelos relatórios recentes do CNJ.

O que se apresenta atualmente é insuficiente, uma mera "diminuição do aumento", sendo necessárias medidas mais rígidas, que gerem impacto no ingresso, e 
não apenas no descesso. Grosso modo, é preciso mudar a cultura processual e não elastecer as metas, aumentar a quantidade de servidores, especialmente quando se consideram as enormes despesas do Estado com a estrutura do poder judiciário. As despesas crescem, o acesso ao judiciário do cidadão também, é verdade, mas sem a qualidade necessária.

Cabe ao pesquisador da área jurídica apresentar soluções diferentes das referidas, que considerem as características do sistema sim, mas acima de tudo possibilitem uma mudança real na qualidade da jurisdição. Investigar sistemas diversos, compreender a cultura processual arraigada nos operadores, implantar uma visão mais aberta, conhecer a própria cultura jurídica, compreendê-la profundamente e questioná-la por seus métodos e por seus resultados.

A fase pré-processual do sistema norte-americano, chamada pretrail, é responsável por uma série de acordos e facilita sobremaneira a vida dos magistrados e das cortes que, não chegam a se debruçar sobre as provas na imensa maioria dos casos. Isso ocorre por razões diversas, mas certamente entre elas figura o altíssimo valor das custas processuais e dos honorários advocatícios.

Diante desse cenário, seria natural concluir que o acesso à justiça é restrito, mas esta conclusão seria precipitada, uma vez que apenas os casos mais complexos ou cujas provas se mostram controversas na fase pretrail processual seguem para julgamento. Os demais casos - aqueles cuja mera aplicação da lei sem grande interpretação é apta a resolver- podem ser resolvidos por instâncias administrativas e moções simples, tornando o acesso à justiça natural, mesmo sem o prosseguimento da ação para a fase processual e consequente julgamento pela corte.

Aqui revela-se o traço diferencial das culturas jurídicas trazidas para estudo, o excepcionalismo marcante da cultura estadunidense, e o costume de importar e adaptar modelos estrangeiros, característico do sistema brasileiro.

Desta forma, visando contribuir com alternativas para resolver o grave problema do acumulo de processos nos juízos de primeira instancia no Brasil, é preciso uma reforma mais profunda do que a que realizou o novo Código de Processo Civil, é preciso arriscar medidas mais profícuas, que interfiram na cultura jurídica do usuário do sistema de justiça brasileiro, que é notadamente atrasada, pois busca o litígio ao mesmo tempo que desconhece os próprios direitos. 
A ideia do presente estudo é considerar um fracionamento sutil do procedimento judicial, dividindo as fases processuais em pré-julgamento e julgamento, deslocando parte da instrução para momento anterior à apresentação do processo para julgamento. Esse deslocamento permitiria afastar gradualmente o magistrado da fase prévia sem perder seus poderes de condução, mas utilizando-os apenas excepcionalmente, quando a situação e o contexto assim requererem.

O desgaste da instrução prévia passa para os advogados, que assumem uma posição interessante perante as partes, adiantando a revelação das provas e a estratégia de atuação. Saliente-se que no direito anglo-americano, onde as fases são assim divididas, a imensa maioria dos casos não chega ao magistrado para julgamento, terminando frequentemente em acordos e desistências.

Será utilizado neste estudo o método hipotético-dedutivo, que se assemelha ao dedutivo na medida em que se reporta ao procedimento racional que transita do geral para o particular e, com o método indutivo, o procedimento experimental. Este modelo e metodologia é atribuído a Popper (2007).

\section{PRETRAIL NO PROCESSO CIVIL DOS ESTADOS UNIDOS}

Nos EUA, a fase anterior ao procedimento judicial propriamente dito é o pretrail, uma espécie de procedimento extraprocessual que permite às partes efetivarem negociações e ao mesmo tempo revelarem reciprocamente provas (discovery) que pretendem apresentar em juízo na fase seguinte (trail). O procedimento, como se verá a seguir de forma mais detalhada, é realizado entre as partes e advogados, sem a participação efetiva do juiz ${ }^{1}$, que apenas interfere quando chamado, geralmente em caso de uma das partes extrapolar seus atos ou abusar de um direito. Entretanto, isso não significa que os atos sejam completamente isentos de oficialidade, pelo contrário, um oficial da corte acompanha a revelação das provas e toma nota das atividades probatórias, conferindo oficialidade aos atos.

\footnotetext{
1 Nos EUA, com o passar do tempo, os juízes (judges) passaram a exercer uma função de administração judicial, e conferiram aos assessores (magistrates) diversas funções judicantes, similares ao que realiza um juiz leigo no Brasil.
} 


\subsection{Funcionamento Padrão do Procedimento Pretrail Norte-Americano}

No procedimento civil norte-americano, a fase anterior à apresentação de provas em juízo é chamada pretrail. Esta fase não contempla a participação direta do magistrado. De fato, quem realiza a maior parte dos procedimentos de produção de provas são os advogados, sob a supervisão de um oficial de cartório que representa o juízo (court officer) e confere oficialidade aos atos.

O juiz pode participar desta fase, no entanto, suas intervenções são excepcionais, motivadas por falhas no andamento processual ou quando uma parte requer a participação do magistrado por observar a violação de um direito. Os juízes devem apenas coibir eventuais abusos perpetrados pelas partes e advogados, bem como violações explícitas de direitos sem, no entanto, interferir diretamente na colheita das provas.

A respeito do ingresso com requerimentos e ações perante a justiça no sistema norte-americano, considerando que um processo judicial gera grandes despesas para as partes, iniciar ações cuja possibilidade de vitória não é evidente é altamente desaconselhável. As despesas mais significativas são custas judiciais e honorários advocatícios. Dessa forma, advogados procuram orientar os clientes a ingressar em contencioso apenas após terem a certeza de terem em mãos um caso sólido e provas robustas.

A respeito das despesas com honorários advocatícios (attorney's fees), convém explicar o funcionamento da chamada american rule. Neste sistema padrão, a parte vencedora obtém da parte derrotada compensação somente pelas custas processuais, sendo que as demais despesas como honorários do advogado, peritos, investigadores especializados, etc, são de responsabilidade da parte, sem direito a compensação. Os honorários advocatícios constituem sem sombra de dúvida as despesas financeiras mais altas do processo (JAMES; HAZARD; LEUBSDORF, 2001, p. 49).

Um caso apto a enfrentar o julgamento, ir à corte, é necessariamente um caso cujas controvérsias não puderam ser resolvidas na fase pretrail, ou seja, nenhuma das partes se convenceu de que poderia sair derrotada em juízo, ou que o resultado do 
julgamento pudesse ser pior do que um acordo ou desistência antecipada. Após a fase pretrail, o juiz fará um juízo prévio das provas apresentadas a justiça e somente admitirá que o caso prossiga se houver solidez das provas e uma verdadeira controvérsia que não pôde ser resolvida entre os advogados das partes. $O$ juiz deve determinar nesse momento o procedimento a ser adotado e analisar o tamanho da questão, explicado pelo termo constrict or expand the flow ${ }^{2}$.

Esse juízo prévio, realizado na fase pretrail, faz com que uma diversidade de questões que pretendiam ir a julgamento seja extinta por acordo, desistência, falta de solidez ou mesmo pela constatação de que os meios de prova não são suficientes para possibilitar um julgamento favorável.

As partes apresentam seus casos à corte mediante pleadings, que são requerimentos direcionados ao juiz. A forma como se pleiteia depende da corte onde a parte o faz, posto que os EUA possuem um Poder Judiciário marcado pelo sistema federativo, o qual permite que os Estados tenham regras específicas de procedimento.

O sistema judiciário norte-americano é dúplice, sendo composto por cortes federais e estaduais que atuam simultaneamente, mantendo a autonomia das cortes estaduais em determinados casos, mas não prescindindo das cortes federais (CARP; STIDHAM; MANNING, 2007. p. 25).

Tal sistema é complexo, mas uma ressalva interessante é que o sistema permite que a maioria dos casos tenha como última instância as cortes de apelação, ou mesmo as cortes distritais, ambas componentes do sistema federal. O que materialmente se pleiteia depende da modalidade de caso que se pretende apresentar à corte.

$\mathrm{O}$ requerimento inicial na fase pretrail tem quatro funções: i) citação; ii) revelação dos fatos (disclosure); iii) formulação da causa; iv) triagem para determinar o tamanho do litígio (constrict or expand the flow). Dependendo do tamanho do litígio, mais ou menos detalhes serão necessários para possibilitar o julgamento da causa. Com efeito, é necessário entender a filosofia por trás da corte onde se pretende discutir o caso antes de se optar por mais ou menos detalhes, bem como averiguar o grau de flexibilidade da mesma (KANE, 2007. p. 86)

2 Tal termo se refere à possibilidade das partes apresentarem à corte um caso mais restrito em que a decisão pode se concentrar em poucas questões sem necessidade de maior dilação probatória ou em um caso expandido, cuja produção de provas na fase pretrail exigirá uma análise mais pormenorizada de fatos e de documentos. 
O padrão do sistema judiciário norte-americano não permite o prosseguimento da controvérsia sem que as partes demonstrem a importância da questão e incapacidade de lidarem com o próprio conflito. Grosso modo, não existe um "case" até que se comprove para a corte que o conflito trazido merece atenção do sistema judiciário e que as provas serão suficientes para determinar um veredicto.

A proposta deste trabalho é averiguar se a aplicação de alguns desses instrumentos seria adequado para colaborar na mudança da cultura judicializante brasileira. A ideia é que a oficialização da fase de acordos e desistências poderia reduzir substancialmente o volume de casos para serem julgados e, via de consequência, de recursos nas instâncias superiores.

A hipótese contrária é de que a notável diferença entre a cultura brasileira e a norte-americana poderia interferir negativamente na utilização do instrumento, uma vez que a cultura jurídica daquele país é de criar soluções próprias para problemas próprios, uma forma bastante pragmática de lidar com os problemas, sendo este pragmatismo elevado também a esfera teórica. No Brasil, a ideia de criar soluções próprias ainda se encontra em um estágio inicial, sendo as adaptações de instrumentos estrangeiros muito mais comum.

\subsection{De Como a Fase Pré-Julgamento Pode Auxiliar na Resolução Célere e Qualitativa dos Conflitos}

Dentre as notáveis diferenças entre as culturas jurídicas aqui discutidas, podese dizer que nos EUA o juiz desempenha um papel diverso do realizado pelo magistrado brasileiro. O juiz norte-americano, por exemplo, conta com institutos que colaboram imensamente na condução do processo, como o contempt of $\operatorname{court}^{3}$, que permite ao magistrado ou à corte aplicar sanções para a parte que desobedecer a ordens judiciais ou deixar de colaborar para o bom andamento do processo. Esse poder da corte é considerado essencial pela suprema corte americana e sem ele o Judiciário norte- americano seria impotente.

\footnotetext{
3 Oriundo do direito Anglo-saxão, é um ato de desprezo pela corte como, por exemplo, a desobediência de uma ordem ou desrespeito contra sua autoridade. O instituto do contempt of court é complexo e sua origem remonta ao século XIV, compreende não somente o ato de desacato propriamente, mas os poderes conferidos ao juízes para que reajam a esse desacato e apliquem aos agentes as sanções cabíveis. Cfr. Adriana Villa-Forte de Oliveira Barbosa e Francisco Vieira Lima Neto. Anotações acerca do contempt of court no direito norteamericano. Revista de Processo, ano 36, nº192, fev. 2011, p. 132.
} 
O juiz norte-americano é, acima de tudo, um profundo conhecedor das regras procedimentais, desempenhando um papel de mediador na maior parte do tempo, antes e depois do julgamento. Os advogados, por sua vez, cumprem o papel de negociadores que utilizam a legislação e os precedentes para estabelecer parâmetros favoráveis a seus clientes e assim pressionar a parte contrária a desistir do caso ou encerrar o caso por acordo.

Boa parte dos acordos realizados na fase pretrail se deve ao procedimento de revelação de provas chamado discovery, que é regulamentada pela federal rule $26^{4}$. Este dispositivo afirma que, no momento anterior ao julgamento, as partes tem o dever de, mesmo sem qualquer solicitação da parte contrária, providenciar o nome, o telefone e o endereço de qualquer pessoa que possa fornecer informações potencialmente úteis para serem utilizadas nos requerimentos e como matéria de defesa, salvo em casos específicos.

Interessante observar que federal rule 26 pela imposição de ampla revelação atribui aos demandantes um dever de absoluta boa-fé. Assim, tal regra apresenta às partes o dever de revelar os fatos e provas previamente, e assim diminuem consideravelmente as possibilidades de surpreender o adversário no momento do julgamento, o que indiretamente privilegia o princípio de paridade de armas entre as partes do litígio.

O sistema common law, por ser formado com fundamentos em pragmatismo mais do que na teoria, rechaça a ideia de que uma parte possa surpreender seu adversário de forma que não tenha aptidão de se defender sobre uma prova da qual não tinha conhecimento, ou de uma revelação inesperada, embora isso possa acontecer. A lei que regula a fase pretrial e a discovery apoia o fato dos casos serem decididos pelas provas dos fatos, e não pela habilidade do advogado em manipular e esconder fatos e testemunhos sem que a outra parte tenha conhecimento.

\footnotetext{
4 26(a) Required Disclosures; Methods to Discover Additional Matter. (1) Initial Disclosures. Except in categories of proceedings specified in Rule 26(a)(1)(E), or to the extent otherwise stipulated or directed by order, a party must, without awaiting a discovery request, provide to other parties: (A) the name and, if known, the address and telephone number of each individual likely to have discoverable information that the disclosing party may use to support its claims or defenses, unless solely for impeachment, identifying the subjects of the information (...)". Cfr. Rule 26 of the Federal Rules of Civil Procedure: General Provisions Regarding Discovery; Duty Of Disclosure. http://www.ilnd.uscourts.gov/_assets/_documents/_forms/_legal/frcpweb/FRC00029.HTM, Acesso em 25-03-2016.
} 
Nesta fase os advogados adquirem informações relacionadas a provas em poder da outa parte antes de serem apresentados em juízo, o que lhes permite terem uma ideia das chances de vitória do próprio caso e do conteúdo probatório de seu adversário. É comum ainda que após a discovery as partes decidam por conduzir um acordo ou mesmo uma desistência voluntária (KERLEY; HAMES; SUKYS, 2005. p. 210).

$\mathrm{O}$ procedimento da discovery dentro da fase pretrail, pode se desdobrar em diversos atos processuais tais como: oitiva da parte contrária, interrogatório de testemunhas e o acesso a documentos e cópias. Ainda antes do julgamento, a s partes devem fornecer informações sobre provas que usará durante o julgamento e os nomes de testemunhas (KANE, 2007, p. 132).

$\mathrm{O}$ adversary system $^{5}$, que pode ser interpretado como o sistema de confronto entre as partes, permite a exposição das provas anteriormente ao julgamento (trial) impedindo uma possível surpresa no momento do julgamento. Para o ideal do sistema norte-americano, ao não se possibilitar que as partes conheçam previamente as provas reciprocamente, estimula-se o acobertamento da verdade dos fatos em detrimento da verdade, prejudicando a busca por decisões justas.

A filosofia do sistema judicial norte-americano permite a revelação total não apenas das provas em si, mas também de informações, documentos e contatos de pessoas que podem de alguma forma colaborar com a elucidação do caso. As informações reveladas nessa fase não serão necessariamente utilizadas ou admitidas em julgamento, mas podem ser úteis na condução de outras provas ou mesmo para distinguir o que deve e o que não deve ser usado na fase de julgamento (KANE, 2007,p. 131).

Um caso que se imaginava extremamente promissor no momento anterior à fase pretrail pode perder credibilidade durante a fase de revelação das provas e negociações prévias. Dessa forma, as partes reavaliam constantemente sua posição no processo, e ao constatar que a vitória não se dará o terreno das provas, evitam o julgamento.

\footnotetext{
5 É o sistema oposto ao inquisitorial, e nele as partes devem comprovar suas alegações e encontrar falhas na argumentação e no conjunto probatório da parte contraria.
} 


\section{O PROCEDIMENTO BRASILEIRO E AS POSSIBILIDADES} APRESENTADAS

O direito processual brasileiro não possui uma fase de pré-julgamento propriamente dita. Antes do ingresso com a ação perante o poder judiciário, pouco se investe em negociações ou mesmo procedimentos de comunicação entre as partes e seus advogados controlados pelos órgãos do Judiciário. Pelo contrário, a comunicação prévia se dá em caráter meramente extraprocessual, não havendo que se falar em regulamentação de praticamente nenhum procedimento fora da competência e presidência do juiz.

\subsection{O Procedimento Monofásico Brasileiro e o Novo CPC}

O CPC de 1973 possibilitava alguns momentos de composição, e embora o novo CPC tenha reforçado o espírito dos órgãos do Judiciário em promover a composição entre as partes como medida de solução do problema da morosidade, a verdade é que se trata de medida paliativa, posto que meramente insere um momento específico para as partes conciliarem antes da resposta ao pedido inicial (contestação).

É assim que dispõe o artigo 334, em seu $\$ 4^{\circ}$ incisos I e II ${ }^{6}$, e como dito acima, embora tenha boas intenções, é medida paliativa, haja vista que às partes já era possível celebrar acordo em qualquer momento do processo. Considera-se paliativa não porque inválida, mas pelo fato de que se trata de uma mera insistência legal, que coloca as partes frente a frente e lhes impõe a realização do um acordo que em geral não atende seus anseios e quando resolve o litígio, o faz apenas na esfera processual, com a extinção da ação, deixando prevalecer o ambiente de insatisfação e de renúncia de direitos.

\footnotetext{
6 “Art. 334. Se a petição inicial preencher os requisitos essenciais e não for o caso de improcedência liminar do pedido, o juiz designará audiência de conciliação ou de mediação com antecedência mínima de

30 (trinta) dias, devendo ser citado o réu com pelo menos 20 (vinte) dias de antecedência. § 4o A

audiência não será realizada: I - se ambas as partes manifestarem, expressamente, desinteresse na composição consensual; II - quando não se admitir a autocomposição.”(CPC 2015)
} 
O novo CPC, no artigo 165 e seguintes, ainda cria centros de conciliação e mediação nos tribunais, e permite que as partes indiquem os conciliadores/mediadores e que se realize por vídeo conferência. Para evitar o não comparecimento das partes em audiência conciliatória, o código estabelece sanção pecuniária (por ato atentatório o exercício da jurisdição), o que parece um pouco exagerado, confirmando a tese de que o acordo nem sempre ocorre de forma espontânea, pelo contrário.

Sendo assim, o que deveria conferir celeridade do procedimento, termina por torná-lo mais longo em boa parte dos casos. A justificativa para o ato de "forçar" o comparecimento das partes e advogados à audiência de conciliação é a celeridade, embora possa ser encarado como uma tentativa de que as partes resolvam por si mesmas seu litígio antes mesmo que o contraditório seja estabelecido. Se assim for, parece faltar um elemento crucial para a composição, que é a informação sobre as provas que as partes pretendem produzir, e este elemento sim poderia ser o principal responsável pela celebração de diversos acordos.

O novo Código de Processo Civil, assim como das metas lançadas pelo CNJ, é dotado de boas intenções, mas faltam ali elementos que façam surgir o interesse genuíno no acordo, sem o qual a política conciliatória estabelecida fica adstrita à esfera da formalidade, e com um caráter meramente impositivo, sem que as partes conheçam o direito que a lei lhes assegura de acordo com as provas que tenham produzido em juízo ou fora dele.

Fazendo rápido contraponto entre o sistema brasileiro e o norte-americano, na fase pretrail norte-americana, as partes efetivamente conhecem as provas da outa parte e vice-versa, tornando a decisão pelo acordo ou desistência muito mais próxima da realidade dos fatos apresentados, colaborando para a sensação de justiça, ou de saída menos penosa. No pretrail, após a exposição das provas (discovery) é realizado um exame de conveniência sobre o prosseguimento do caso (advisability) e isso permite um julgamento antecipado (settling early)(KERLEY; HAMES; SUKYS, 2005. p. 214).

No processo civil brasileiro, por sua vez, tanto as partes quanto os juízes estão mais sujeitos a serem surpreendidos por manobras processuais e fatos não conhecidos até o momento do julgamento. Isso pode dar margem à má-fé das partes ou de seus procuradores, gerar ações ou defesas infundadas, produzir atos processuais inúteis, além 
de dificultar o cumprimento das garantias processuais constitucionais e contribuir para a morosidade da prestação judicial.

O procedimento adotado pelos Juizados Especiais Cíveis (lei no 9099/95), que dá ao juiz a possibilidade de proferir sentença na própria audiência de instrução, o depoimento das partes ou a oitiva das testemunhas pode ser fator decisivo e surpreender uma das partes ou seu advogado, que, sem ter o conhecimento prévio do conteúdo da prova, pode não ter real oportunidade para realizar a devida e adequada impugnação e exercer o direito constitucional à prova contrária ${ }^{7}$.

A crítica às soluções adotadas pela legislação até então se baseia exatamente no ponto levantado no parágrafo anterior, pois a lei, visando dar celeridade ao procedimento, termina por interferir na qualidade da jurisdição, posto que uma solução rápida nem sempre é uma solução justa, e o ideal é alcançar o máximo possível de cada garantia processual.

Com efeito, como no sistema processual brasileiro não há separação das fases de pré-julgamento e julgamento, isso permite que surpresas ocorram e o jogo de estratégias prevaleça sobre a tutela do direito material. Ao contrário do legislador brasileiro, no sistema norte-americano a possibilidade de se vencer o caso com artimanhas processuais que venham a prejudicar a outra parte é sistematicamente vedada pelas cortes, que privilegiam o direito material das partes em detrimento de armadilhas processuais.

Nos Estados Unidos, aliás, o sistema de commom law pleading foi praticamente abolido e substituído pelo code pleading e pelo federal pleading em razão destes sistemas prestigiarem a análise de questões de mérito, ao invés do denominado game of wits.

Game of wits é o jogo de estratégias que advogados costumam submeter seus clientes e o próprio sistema judiciário no intuito de se isentarem de um julgamento que considere em maior grau a justiça das decisões. O game of wits é, pois, uma sequência de artimanhas que visa surpreender a parte contrária, no sentido de lhe dificultar as possibilidades de defesa, impondo um resultado frequentemente injusto ou descomprometido com o direito material.

\footnotetext{
7 Sobre o direito à prova contrária, verrir, entre outros: COMOGLIO, Luigi Paolo; FERRI, Corrado; TARUFFO, Michele. Lezioni sul processo civile. Bolonha: Il Mulino, 1995. p. 70-71; CAMBI, Eduardo. Direito constitucional à prova no processo civil. São Paulo: RT, 1999. p. 137)
} 
Game of wits é o jogo de estratégias que advogados costumam submeter seus clientes e o próprio sistema judiciário no intuito de se isentarem de um julgamento que considere em maior grau a justiça das decisões. O game of wits é, pois, uma sequência de artimanhas que visa surpreender a parte contrária, no sentido de lhe dificultar as possibilidades de defesa, impondo um resultado frequentemente injusto ou descomprometido com o direito material.

A discovery stage da fase pretrail propicia às partes e ao julgador o conhecimento e a noção sobre o tamanho do caso e restringe as questões a serem julgadas, o que permite o julgamento antecipado da causa ou, ao menos, ajuda a torná-lo mais transparente (KANE, 2007, p. 131).

\subsection{Possíveis Consequências d a Adoção do Sistema Bifásico no Procedimento Processual Civil Brasileiro}

A política adotada pelo novo CPC no intuito de diminuir a quantidade de processos a serem julgados mediante a realização de acordos foi a imposição de uma fase de acordos antes da resposta do réu, o que seria uma boa ideia se as partes já conhecessem o conjunto probatório que lhes permitisse avaliar juntamente com seus advogados as chances de vencer e assim aceitar proposta de acordo da parte oponente ou lhe oferecer uma proposta. Este procedimento é falho pelos seus próprios fundamentos, mas é de se admitir que ele possa resultar em eventuais acordos, mesmo que as partes não estejam absolutamente convencidas de sua posição no processo.

A adoção de uma fase em que as partes pudessem trocar informações, revelar suas provas e efetivar negociações poderia aumentar consideravelmente a quantidade de acordos e o nível de satisfação do resultado. A fase pretrail possui duas características de ordem prática extremamente eficazes: i) a quantidade de processos encerrados mesmo antes da fase de julgamento, posto que ao observar as provas potenciais e as já coletadas da outra parte, os litigantes preferem evitar maiores despesas e desgaste público, o que, via de regra, estimula a autocomposição; ii) a redução do volume de processos após a fase pretrial permite ao juiz se ater com mais atenção aos casos 
resultantes de um processo de formulação de provas mais sólido, o que aprimora a qualidade da prestação jurisdicional e a qualidade dos serviços prestados pelo Poder Judiciário.

Tal procedimento obviamente alivia a Justiça e encurta a duração do processo. Ora, primeiro, é realizado fora da Corte, sem a presença do juiz, o que poupa tempo e recursos da Justiça; segundo, a causa só vai a julgamento se efetivamente madura: se o autor (plaintiff) não possuir um mínimo de provas que sustentem a sua alegação e indiquem a possibilidade de um júri decidir a seu favor, o réu (defendant) pode requerer julgamento sumário negando o pedido e encerrando o processo (motion for summary judgment); terceiro, ele permite que os advogados elaborem mais adequadamente as suas teses e as provas que a sustentam, submetendo à decisão da Corte apenas o que for controverso; e, quarto, e talvez o mais importante, permite que os advogados avaliem os pontos fortes e fracos que sustentam as suas teses e os riscos jurídicos decorrentes bem como negociem um acordo no intuito de minimizar esses riscos (CARDOSO, 2014).

As desistências e os acordos realizados nessas condições trazem às partes envolvidas a certeza de que não conseguiriam solução mais vantajosa de outra maneira, o que contribui para a pacificação social ${ }^{8}$. No caso do Brasil, devido ao número excessivo e crescente de processos que chegam ao Poder Judiciário, é necessário pensar em formas mais efetivas de aperfeiçoar a prestação jurisdicional. Este pensamento é corroborado por importantes autores, como Candido Rangel Dinamarco, que diz:

A ciência processual brasileira vive, em tempos presentes mais o que nunca, uma grande necessidade de tomar consciência das realidades circundantes representadas pelos institutos e conceitos processuais de outros países, para busca de soluções mais adequadas aos problemas da nossa justiça [...] tais fatores de pressão tornam imperiosas as comparações jurídicas que sempre foram úteis ao aprimoramento institucional do direito de um país e agora revelam-se como verdadeira necessidade e tornam-se indispensáveis sob pena de se caminhar às cegas e correr desnecessários riscos de fracasso e de injustiças (DINAMARCO, 2000, p. 762-763).

A cultura processual brasileira é de judicialização dos litígios, ou seja, envolve o raciocínio de que as causas devem ser resolvidas pelo Poder Judiciário (exegese do art. 5o, inc. XXXV, da Constituição Federal). Esta cultura possivelmente é uma das responsáveis pelo abarrotamento de processos e consequentemente pela menor eficácia da prestação jurisdicional no Brasil.

8 Evitando um fenômeno conhecido por alguns doutrinadores como "litigiosidade contida" (Kazuo Watanabe, in Juizado especial de pequenas causas: Lei 7.244, de 7 de novembro de 1984. São Paulo: Revista dos Tribunais, 1985, p. 2-3), que é o resultado de uma descrença generalizada da população no sistema de justiça e resultar em outros problemas sociais de ordem prática aos auqis inicialmente não estavam relacionados. 
A mudança dessa cultura requer a apuração da técnica de resolução efetiva e qualitativa de conflitos.

A estratégia das autoridades judiciárias brasileiras -especialmente o $\mathrm{CNJ}$ - em desenvolver campanhas de incentivo a celebração de acordos, são importantes, porém, revelam resultados tímidos. Somente a aplicação prática de novas técnicas poderia trazer uma resposta adequada, mas é correto dizer que a mudança passa pela alteração da legislação com o desmembramento do trâmite judicial em duas fases, permitindo a desoneração do magistrado da fase de produção de provas como forma de permitir a composição das partes sem desrespeito a qualquer garantia de acesso à justiça.

A efetividade da fase de pré-julgamento nos EUA passa pelo sistema de revelação das provas entre as partes (discovery), e após esta fase o índice de encerramentos aumenta substancialmente. A filosofia do sistema processual norteamericano procura evitar surpresas, o que impõe senão a revelação prévia das provas, ao menos informações seguras que possam conduzir a sua admissibilidade em juízo (KANE, 2007. p. 129).

A utilização da discovery no sistema norte-americano tem níveis muito elevados, chegando a $85 \%$ a incidência. Devido sua ampla utilização, é correto dizer que o processo civil como hoje se apresenta nos EUA é dependente dos mecanismos da discovery na fase pretrail (WILLGING; SHAPARD; STIENSTRA; MILETICH, 1997, p. 03).

Uma reforma nesse sentido no Brasil deve levar em conta uma maior responsabilidade das partes e de seus procuradores na gestão dos litígios, ampliar a possibilidade de resolução do litígio na fase extrajudicial e permitir aos litigantes conhecer suas chances de sucesso em eventual demanda judicial, aceitando o risco e o ônus de um processo judicial que, em tempo razoável, consiga resolver o litígio.

Para o professor Flávio Luiz Yarshell, as regras referentes à distribuição do ônus da prova possuem, além da função de esclarecimento do juízo, um instrumento pelo qual os interessados avaliam suas chances processuais, riscos e encargos a que estão submetidos, e pelo qual norteiam sua conduta para evitar uma decisão (judicial) imperativa (YARSHELL, 2009. p. 137). 


\section{CONSIDERAÇÕES FINAIS}

A constatação de que as medidas até aqui tomadas pelos órgãos e autoridades judiciárias têm colaborado apenas para a aceleração desregrada do procedimento sem interferir na qualidade da jurisdição, bem como de que o acesso mais amplo aos órgãos do poder judiciário causa um contingente difícil de ser controlado, obrigam a considerar soluções mais ousadas, como técnicas processuais para aprimorar o sistema judiciário brasileiro. O procedimento probatório do Código de Processo Civil de 1973 não era adequado para evitar o congestionamento de processos na justiça brasileira.

O Novo Código de Processo Civil trouxe avanços em relação às possibilidades de conciliação, porém, não adotou o modelo bifásico norte-americano, não previu uma fase pré-processual voltada ao compartilhamento dos elementos probatórios entre as partes. O Código se aproximou da ideia desta pesquisa apenas no art. 381, inc. II e III, quando admitiu a produção antecipada de provas para evitar o ajuizamento da ação ou facilitar a composição entre as partes, mas não com regra, e sim excepcionalmente, e ainda sim em procedimento processual, e não extraprocessual, o que de imediato onera o juízo.

Os resultados atingidos pelo procedimento pretrail nos EUA levam a crer que para se obter resultados mais eficientes no Brasil, seria necessário aperfeiçoar a legislação processual para subdividir o procedimento em duas fases: a de pré- julgamento e a de julgamento. Tal exercício permitiria ainda, reforçar a adoção pelas partes de princípios de boa-fé processual em sentido objetivo, para melhor conduzir o comportamento ético das partes e dos advogados no processo.

O fracionamento das fases e a revelação prévia de provas tem o potencial de empoderar os advogados e atribuir maior participação às partes, aproximando-as da realidade processual. Como consequência positiva, desonera o magistrado sem necessariamente deslocar o juízo do controle dos atos processuais. 


\section{REFERÊNCIAS}

BARBOSA, Adriana Villa-Forte de Oliveira; NETO, Francisco Vieira Lima, Anotações acerca do contempt of court no direito norte-americano. Revista de Processo, ano 36, nº192, fev. 2011.

CAMBI, Eduardo. Direito constitucional à prova no processo civil. São Paulo: RT, 2001.

CARDOSO, César. O pré-julgamento (pretrail) e a conciliação como instrumentos de desoneração do sistema judicial norte-americano: um paralelo com o sistema brasileiro. Disponivel em: www.agu.gov.br/page/download/index/id/9923695. Acesso em ago 2014.

CARP, Robert A. STIDHAM, Ronald; MANNING, Kenneth L.. Judicial Process in America. 7. ed. Washington DC: CQ press, 2007.

COMOGLIO, Luigi Paolo; FERRI, Corrado; TARUFFO, Michele. Lezioni sul processo civile. Bolonha: Il Mulino, 1995.

DINAMARCO, Cândido Rangel. Fundamentos do processo civil moderno, vol. I, 3. ed., São Paulo: Malheiros, 2000.

JAMES, Fleming; HAZARD, Geofrey C. Jr.; LEUBSDORF, John. Civil Procedure, 5 ed. Foundation Press, 2001.

KANE, Mary Kay. Civil procedure. $6^{\text {a }}$ ed. St. Paul, MN: Thomson West, 2007

KERLEY, Peggy; HAMES, Joanne B.; SUKYS, Paul A. Civil litigation. 4. ed. Nova Iorque: Thomson \& Delmar Learning, 2005

POPPER, Karl. A lógica da pesquisa científica. São Paulo: Cultrix, 2007. WATANABE, Kazuo; et. al. Juizado especial de pequenas causas: Lei 7.244, de 7 de novembro de 1984. São Paulo: Revista dos Tribunais, 1985.

WILLGING, Thomas E.; SHAPARD, John; STIENSTRA, Donna; MILETICH, Dean. Discovery and Disclosure Practice, Problems, and Proposals for Change: A Casebased National Survey of Counsel in Closed Federal Civil Cases. Reports on Discovery for the Advisory Committee on Civil Rules of the Judicial Conference of the United States. Federal Judicial Center, 1997.

YARSHELL, Flávio Luiz. Antecipação da prova sem o requisito da urgência e direito autônomo à prova. São Paulo: Malheiros, 2009. 